\title{
Identificación política y valores profesionales en tensión en la práctica periodística en dos salas de redacción de la ciudad de Buenos Aires
}

\author{
Laura Rosenberg \\ laura.rosenberg85@gmail.com
}

Consejo Nacional de Investigaciones Científicas y Técnicas (CONICET) - Universidad Nacional de General Sarmiento

Recibido: 14 de mayo de 2018 Aceptado: 2 de noviembre de 2018.

\section{Resumen}

El objetivo del artículo es analizar las tensiones que se manifiestan entre la identidad profesional y la identificación política de los periodistas en las salas de redacción de Página/12 y Tiempo Argentino entre 2011 y 2015, diarios cuyas líneas editoriales acompañaron las políticas gubernamentales. Desde un abordaje etnográfico (Restrepo, 2016), el artículo aborda confluencias y tensiones relativas a la identificación política de los periodistas y los medios. El análisis de esta cuestión permite reconstruir los valores que los primeros destacan como propios del ejercicio de su práctica profesional. Para ello, se recuperan los aportes de la sociología del trabajo del interaccionismo simbólico (Abbott, 1993; Becker, 2006, Becker 2009; Becker \& Strauss, 1956; Becker, Geer, Hughes \& Strauss, 1961; Hughes, 2012 y Geer, 1972) y del enfoque dramatúrgico (Goffman, 2006) para analizar dos instancias diferenciadas del proceso de identificación. La primera remite al reclutamiento de jóvenes periodistas y el rol que jugó en la conformación de sus expectativas de ingresar en el mundo periodístico la afinidad entre su identificación política y la línea editorial del medio donde ingresaron a trabajar. La segunda describe situaciones del trabajo cotidiano de producción de las noticias dentro de cada una de las salas de redacción, donde se registraron discusiones en torno al enfoque para la presentación de los hechos políticos y se generó un distanciamiento respecto a la línea editorial del medio. A partir del análisis de estas situaciones, veremos, por ejemplo, que los criterios de noticiabilidad no siempre operan como punto de partida de la labor periodística, sino que son permanentemente sujetos a discusión. De este modo, en lugar de analizar las tareas cotidianas en las salas de redacción a la luz de criterios definidos a priori, será la reflexión continua que realizan los propios actores en su labor lo que nos permitirá reconstruir las normas y los valores propios de la deontología periodística.

Palabras clave: periodismo, prensa gráfica, noticiabilidad, identidad, rutinas periodísticas. 


\title{
Political identification and professional values in tension in the journalistic practices of two newsrooms in the City of Buenos Aires
}

\begin{abstract}
The goal of this article is to look at the tension between professional identity and political identification as experienced by journalists in the newsrooms of Página/12 and Tiempo Argentino between 2011 and 2015, when the editorial lines of both newspapers were in tune with the national government's policies. From an ethnographic perspective (Restrepo, 2016), this article addresses the tensions and intersections between journalists' political identification and that of their media outlets. By analyzing this topic, we can appreciate what values the former identify as part of their professional practice. To do this, we returned to the contributions of labor sociology, specifically to those on symbolic interactionism (Abbott, 1993; Becker, 2006; Becker, 2009; Becker, Geer, Hughes, y Strauss, 1961; Becker y Strauss, 1956; Hughes, 2012 y Geer, 1972) and dramaturgical analysis (Goffman, 2006), in order to study two distinct moments in the process of identification. The first involves the hiring of young journalists and how their expectations, upon entering the world of journalism, are affected by the affinity between their own political identification and the editorial line of the newspaper they now work for. The second moment describes situations, in everyday content production inside the newsroom, in which journalists discuss their newspaper's stance in relation to certain political events, leading to deviations from the editorial line. After studying these moments, we shall find, for example, that criterias for newsworthiness are not always starting points for journalistic work but are instead frequently called into question. Rather than using predefined parameters to analyze daily newsroom tasks, we shall reconstruct the norms and values of journalistic ethics by looking at the continuous self-reflection undertaken by journalists during their everyday work.
\end{abstract}

Keywords: journalism, print press, newsworthiness, identity, journalistic routines.

\section{Identificação política e valores profissionais em tensão na prática jornalística em duas redações da cidade de Buenos Aires}

\section{Resumo}

O objetivo do artigo é analisar as tensões que surgem entre a identidade profissional e a identificação política dos jornalistas nas redações dos jornais Página/12 e Tiempo Argentino entre 2010 e 2015 durante o governo de Cristina Fernández de Kirchner. A partir de uma abordagem etnográfica, o artigo aborda confluências e tensões relacionadas à identificação política de jornalistas e da mídia, cuja análise nos permite reconstruir os valores que os primeiros destacam como característica do exercício de sua prática profissional. Para isso, recuperam-se as contribuições da sociologia do trabalho do interacionismo simbólico e a abordagem dramatúrgica para analisar duas instâncias diferenciadas do processo de identificação. A primeira refere-se ao recrutamento de jovens jornalistas nas redações e ao papel que desempenha, na formação de suas expectativas de ingressar no mundo jornalístico, a afinidade entre sua identificação política e a linha editorial do meio em que entraram para trabalhar. A segunda instância descreve situações do cotidiano de produção noticiosa em cada uma das redações, onde foram registrados pontos de vista sobre a abordagem da apresentação de eventos políticos e gerou-se um distanciamento da linha editorial do meio. A partir da análise dessas situações, veremos, por exemplo, que os critérios de noticiabilidade nem sempre operam como ponto de partida do trabalho jornalístico, mas estão permanentemente sujeitos à discussão. Dessa forma, em vez de analisar as tarefas cotidianas nas redações à luz de critérios definidos a priori, será a reflexão contínua realizada 
pelos próprios atores em seu trabalho, que nos permitirá reconstruir os valores e as normas do trabalho próprios da deontologia jornalística.

Palavras chave: jornalismo, imprensa gráfica, noticiabilidade, identidade, rotinas jornalísticas.

\section{Introducción}

Este artículo se propone analizar las tensiones manifiestas en las salas de redacción de los diarios Página/12 y Tiempo Argentino entre los valores profesionales de los periodistas y la línea editorial de dos medios que resultaron afines a los gobiernos de Cristina Fernández de Kirchner (períodos 2007-2011 y 2011-2015). ${ }^{1}$ Como punto de partida, se presenta una situación que, en principio, puede resultar paradojal: tales tensiones se gestaron a pesar de que en la generalidad de los casos los periodistas de ambos diarios manifestaron su afinidad con el lineamiento político-ideológico de estos medios, e incluso algunos de ellos se identificaron políticamente con el kirchnerismo; sin embargo, en la práctica laboral cotidiana, cuestionaron abiertamente sus respectivas líneas editoriales.

Una primera hipótesis que formulamos frente a esta cuestión es que las críticas de los periodistas hacia los medios informativos eran efectuadas cuando observaban que la asociación de los medios con un partido o proyecto político podía atentar contra el "buen desempeño" del periodismo, es decir, contra los valores profesionales que consideraban que debían regir el trabajo. En los casos que aquí se presentan, se observó que los periodistas entrevistados explicaban que la proximidad político-ideológica de Página/12 y Tiempo Argentino con el partido gobernante les había valido su caracterización como medios oficialistas, lo que ponía en jaque una serie de valores deontológicos del periodismo y el prestigio de estos diarios, así como su propia reputación como profesionales de prensa.

Desde un abordaje etnográfico (Restrepo, 2016), que comprendió la observación participante en las salas de redacción de Tiempo Argentino y Página/12 entre 2011 y 2015, y sesenta y cuatro entrevistas a periodistas de ambos medios y miembros de los espacios académicos que transitaron los colaboradores más jóvenes, se describirán confluencias y tensiones relativas a la identificación política de los periodistas y del medio. El análisis permite reconstruir los valores que los primeros destacan como propios del ejercicio de su práctica profesional. En este sentido, no nos remitiremos a

\footnotetext{
Teniendo en cuenta las dimensiones de sus respectivos staffs y la circulación neta de Página/12 y Tiempo Argentino se puede afirmar que se trata de empresas periodísticas de estructuras intermedias. De lunes a viernes, la circulación de ambos diarios oscilaba entre los diez mil y los trece mil ejemplares durante el período que abarca este estudio. Sus staffs contaban con doscientos trabajadores aproximadamente. A pesar de que estas cifras resultaban muy inferiores a las de los diarios Clarín y La Nación-que lideraban el mercado de la prensa con más de doscientos mil y cien mi ejemplares vendidos, respectivamente, según diversas fuentes consultadas-, sostenemos que Tiempo Argentino y Página/12 tenían una estructura intermedia porque sus dimensiones y circulación superaban largamente las propias de los medios más pequeños, algunos de los cuales no contaban con más de una docena de periodistas.
} 
Laura Rosenberg

Identificación política y valores profesionales en tensión en la práctica periodística en dos salas de redacción de la ciudad de Buenos Aires

formulaciones a priori sobre la deontología periodística que puedan estar presentes en manuales de periodismo o en investigaciones previas sobre la temática, sino que los valores y las normas a los que aquí nos referiremos son aquellos que han sido destacados por los entrevistados en este estudio y que han sido puestos en juego en sus rutinas de trabajo en las salas de redacción de ambos diarios. ${ }^{2}$

Para llevar a cabo nuestro objetivo, diferenciamos dos instancias en la investigación: la primera se sitúa en el reclutamiento de jóvenes periodistas en las salas de redacción, y en el rol que jugó la afinidad entre su identificación política y la línea editorial del medio donde comenzaron a trabajar en la conformación de sus expectativas de ingresar en estos medios y no en otros. La segunda instancia describe situaciones del trabajo cotidiano de producción de las noticias dentro de cada una de las salas de redacción, donde se registraron discusiones en torno al enfoque adoptado para la presentación de los hechos políticos y se generó un distanciamiento respecto a la línea editorial del medio. Este distanciamiento se plasmó en las críticas a la dirección del diario cuando los periodistas observaban que las lógicas del campo político se imponían sobre la aplicación práctica de los valores profesionales compartidos en el mundo periodístico. Para aprehender la problemática se indagó sobre la implementación de los criterios de noticiabilidad, entendidos como reglas prácticas que permiten a los periodistas identificar y jerarquizar acontecimientos políticos, sociales, económicos o culturales susceptibles de ser convertidos en noticias (Wolf, 1987; Martini, 2004).

A continuación, se expone el enfoque de análisis sobre los procesos identitarios recuperados en esta investigación, que responden centralmente a perspectivas desarrolladas en el marco del interaccionismo simbólico y corrientes afines, como el enfoque dramatúrgico de Erving Goffman (2006).

\section{El análisis de la identificación desde un enfoque interaccionista}

Para comprender las tensiones entre la identificación política y la identificación profesional de los periodistas, retomaremos los aportes teórico-metodológicos de corrientes que destacan el carácter situado de la conformación identitaria. Específicamente, nos referiremos a los trabajos de la Escuela de Chicago, que no solamente han desarrollado una sociología del trabajo atenta a los sentidos compartidos, a la incorporación de los roles y los aprendizajes adquiridos por los individuos en sus espacios laborales, sino que también han abordado los procesos de identificación desde una perspectiva constructivista.

Como veremos más adelante, valores como objetividad, neutralidad e imparcialidad, habituales en los estudios clásicos del newsmaking de las décadas del setenta y el ochenta, no aplican a los casos del presente artículo. 
Austral Comunicación

Volumen 7 número 2 (diciembre de 2018): 201-228. ISSN 2313-9129

Autores como Andrew Abbott, Howard Becker, Everett Hughes, Robert Park y Anselm Strauss hicieron hincapié en la dimensión interaccional, en los vínculos y las redes que los individuos establecen con los demás en el marco de sus trayectorias ocupacionales. Entre algunos de estos estudios, se destacan los de Abbott (1993); Becker (2006, 2009); Becker \& Strauss (1956); Becker, Geer, Hughes \& Strauss (1961); Geer (1972) y Hughes (2012). En estos trabajos, las carreras ocupacionales, lejos de ser analizadas en términos de trayectorias individuales, son consideradas como la perspectiva móvil desde la cual las personas perciben su vida como un todo, se orientan a sí mismas con referencia a un orden social e interpretan el significado de los atributos, las acciones y las cosas que les suceden. Además, se asume que en las carreras inciden las redes de cooperación que los actores construyen con otros integrantes del mundo laboral. El análisis de las situaciones de interacción social resulta, desde esta perspectiva, una condición sine qua non para arribar a la comprensión de la socialización laboral.

Hughes (2012) traza un vínculo entre los campos de estudio sobre el mundo laboral y los procesos identitarios, al sostener que el trabajo es un componente fundamental a la hora de definir la identidad social. Según este autor, los roles desempeñados en las tareas cotidianas coadyuvan con el proceso de desarrollo de la personalidad en la medida en que "el individuo adquiere una concepción consistente de sí mismo en relación con otras personas" (p. 57). En sintonía con esta concepción, Park (1950) sostiene que todas las personas ejercen constantemente roles, y a partir de su ejecución cada uno se conoce con el otro, al tiempo que se conoce a sí mismo. Estas definiciones resultan centrales en el desarrollo de la concepción de Goffman (2006) sobre la identidad del yo, con la cual se refiere al "sentido subjetivo de su propia situación, continuidad y carácter que un individuo alcanza como resultado de las diversas experiencias sociales por las que atraviesa" (p. 126).

A partir del análisis que Goffman (2006) realiza sobre las personas estigmatizadas -tema que no es materia de análisis en nuestro artículo, pero cuyo abordaje aportó definiciones sobre la cuestión identitaria que aquí nos resultan útiles-, el autor cuestiona la idea de biografía como único relato posible sobre las experiencias vitales y la identidad de los actores. En cambio, propone analizar la multiplicidad de yoes que se manifiestan en las distintas situaciones atravesadas. Esta mirada es la que retomamos aquí para desentrañar la aparente contradicción entre la identificación política y la profesional de los periodistas, y para pensar en la presencia de cuestiones relativas al campo político que se hacen presentes en el trabajo cotidiano en las redacciones y el modo como son resignificadas por quienes se desempeñan en la prensa.

Otra cuestión relevante para el análisis de los procesos de identificación remite a los efectos, en términos de autopercepción, que genera la participación en distintos grupos. El sentimiento de pertenencia a un colectivo resulta de la existencia de lazos de 
Laura Rosenberg

Identificación política y valores profesionales en tensión en la práctica periodística en dos salas de redacción de la ciudad de Buenos Aires

solidaridad que se afianzan a partir de la existencia de intereses y miradas compartidas por los integrantes de un grupo. Ambos pueden orientar el curso de las carreras profesionales de las personas. En el caso que aquí analizaremos, veremos que los jóvenes periodistas se mostraron interesados en integrar las salas de redacción de los diarios con los cuales ellos se sentían identificados como lectores. En una primera instancia de su carrera, se mostraban más cercanos a la línea editorial de estos medios que a la de sus competidores, lo cual motivó en muchos casos su acercamiento a esas empresas periodísticas.

Si la pertenencia a un equipo, grupo u organización resulta fundamental en la constitución identitaria de las personas, también lo son las oposiciones a otros grupos y organizaciones del mundo social, las cuales pueden expresarse a través de la distinción entre un ellos y un nosotros (Bauman \& May, 2007). El nosotros se expresa en el grupo de pertenencia con cuyos integrantes se comparten tanto motivaciones como una definición de la situación; el ellos caracteriza al conjunto al que no se pertenece ni se desea hacerlo, y sobre el cual se depositan sentimientos de antipatía o incluso de explícito rechazo. Sobre la base de esta oposición, destacan Bauman y May, se produce la autoidentificación: "Son los recursos que obtenemos de nuestro entorno los que permiten la autoidentificación: no hay un núcleo fijo para nuestras identidades. Como tales, las oposiciones se convierten en herramientas de las que nos servimos para dibujarnos el mundo" (p. 44). De este modo, el ellos y el nosotros son opuestos inseparables, ya que se torna imposible pensar el uno sin el otro; son antagónicos que le dan sentido y tornan real a su oponente. El ellos constituye, entonces, la condición de posibilidad de la existencia del nosotros.

Aquí se llevará a cabo un análisis que atiende al carácter situado del proceso de identificación de los periodistas, que nos permitirá explicar las tensiones explicitadas entre sus afinidades políticas y la defensa de la deontología profesional. Como veremos, en la definición de una identidad profesional resultará central la diferenciación respecto a quienes varios periodistas identificaron como "los de arriba" (la dirección periodística del diario, responsable de la línea editorial del medio).

Como se planteó anteriormente, para cumplir nuestro objetivo se implementó un abordaje de corte etnográfico, que implicó la realización de observaciones en los espacios de trabajo de los periodistas y entrevistas a diversos integrantes del mundo periodístico (tanto de la esfera laboral como de la académica). La opción por esta forma de aproximación responde a las características que ella presenta, según formula Restrepo (2016): “La etnografía como metodología, como encuadre, estaría definida por el énfasis en la descripción y en las interpretaciones situadas [...] buscaría ofrecer una descripción de determinados aspectos de la vida social teniendo en consideración los significados asociados por los propios actores" (p. 32). 
Austral Comunicación

Volumen 7 número 2 (diciembre de 2018): 201-228. ISSN 2313-9129

Se efectuaron observaciones en las salas de redacción de Página/12 y Tiempo Argentino durante las jornadas de trabajo ${ }^{3}$ y en coberturas externas, con el objeto de acceder no solo a los vínculos cotidianos que se establecían en el interior de estos diarios, sino también a los construidos con las fuentes de información y colegas de otros medios. De allí fue posible analizar que el proceso de socialización laboral no transcurre únicamente puertas adentro de las redacciones, sino que los lazos que se construyen con otros actores del mundo periodístico son relevantes para el aprendizaje de la práctica periodística de los más jóvenes, su autopercepción como profesionales y, en general, para la elaboración de representaciones sobre el rol social del periodismo. ${ }^{4}$

Se realizaron tres tipos de entrevistas: en profundidad, no directivas o informales, y semiestructuradas. Las primeras fueron efectuadas a jóvenes redactores de Tiempo Argentino y a pasantes de Página/12 (tales son las denominaciones respectivas para los empleados con poca o nula experiencia previa), a fin de indagar sobre las motivaciones que los llevaron a insertarse en el mundo periodístico, conocer sus trayectorias académicas, sus experiencias laborales previas al ingreso en los diarios y los aprendizajes recibidos durante la primera etapa de su socialización laboral. Simultáneamente, se realizaron entrevistas semiestructuradas a otros integrantes de ambos diarios y a miembros de espacios académicos transitados por los jóvenes periodistas (fundamentalmente, docentes de carreras de comunicación y personal académico vinculado con el área de pasantías educativas). Estas citas permitieron conocer la cultura organizacional de cada empresa, las percepciones sobre las condiciones de trabajo e inserción de pasantes, los lazos entre periodistas con distintas jerarquías en la sala de redacción, entre otras temáticas. Con algunos entrevistados se mantuvieron varios encuentros en distintas instancias de la investigación -algunos de los cuales revistieron la modalidad de entrevistas no directivas-, a fin de consultar por cambios sustantivos en las respectivas empresas. Las entrevistas no directivas o informales se materializaron a lo largo de todo el trabajo de campo y fueron incorporadas como notas de campo en toda la investigación.

La tradición de incorporar la etnografía a la investigación sobre la producción noticiosa fue desarrollada de manera central por los estudios norteamericanos y británicos sobre newsmaking, entre los cuales se pueden destacar los trabajos de Altheide (1984), Epstein, (2000), Gans (2004), Golding \& Elliott (1979), Schlesinger (1987) y Tuchman (1983), entre otros. Estos análisis han recurrido a la observación participante

\footnotetext{
Las observaciones fueron realizadas en diferentes secciones del diario, desde un escritorio que no estuviera ocupando ningún periodista. Esto facilitaba el acceso de primera mano a la organización del trabajo cotidiano y a las interacciones entre periodistas con distintos cargos dentro de la sección. Se participaba ocasionalmente de conversaciones sociales que ellos mantenían durante la jornada de trabajo.

4 Los periodistas (tanto quienes fueron entrevistados como quienes no) estaban al tanto de los motivos de la presencia de quien escribe en la sala de redacción y de los objetivos de la investigación que se llevaba a cabo. Se compartió el texto final de los resultados con los entrevistados.
} 
Laura Rosenberg

Identificación política y valores profesionales en tensión en la práctica periodística en dos salas de redacción de la ciudad de Buenos Aires

dentro de los espacios de trabajo de periodistas de prensa y televisión. Esta técnica les ha permitido, por un lado, "recoger y obtener sistemáticamente las informaciones y los datos fundamentales sobre las rutinas productivas operantes en la industria de los media" (Wolf, 1987, p. 211); por el otro, la observación participante, junto con las entrevistas, les ha habilitado el acceso "al modo en que los trabajadores de las noticias ven el mundo y hacen su trabajo" (Altheide, 1984, p. 9). Al considerar la noticia como una construcción social -y no como un "reflejo" de la realidad-, las etnografías llevadas a cabo en medios periodísticos por la escuela del newsmaking se abocaron a describir en detalle las rutinas productivas, para demostrar que las noticias resultan de un proceso de trabajo colectivo que se realiza en el marco de organizaciones.

La investigación que aquí presentamos sobre las tensiones entre la identificación política y deontológica de los periodistas de prensa se vale de los aportes teóricos de las perspectivas interpretativas reseñadas anteriormente y el enfoque metodológico de los estudios del newsmaking. En el siguiente apartado haremos una breve historización de los medios de prensa en cuestión, para luego iniciar el análisis de las expectativas que los periodistas más jóvenes manifestaron respecto a la inserción laboral en el mundo periodístico.

\section{Página/12 y Tiempo Argentino: expectativas sobre la inserción laboral en "el diario de los derechos humanos" o en "un diario nuevo"}

El artículo propone un análisis comparativo entre los procesos de identificación de los periodistas de dos diarios de distribución nacional: Página/12 y Tiempo Argentino. El cotejo entre estos medios, que tienen trayectorias diferentes en el campo periodístico, se explica por la similitud observada en el examen de la identificación política y deontológica de los periodistas, y las tensiones manifiestas entre una y otra.

En la comparación destacamos, en primer lugar, dos puntos en común entre las organizaciones periodísticas: durante el período analizado, por un lado, ambas eran empresas de dimensiones intermedias en el rubro de la prensa gráfica y, por otro, sus líneas editoriales resultaron afines al gobierno nacional, razón por la cual sus competidores los caracterizaron eufemísticamente como medios oficialistas. En segundo lugar, se consideraron dos diferencias centrales entre ambos medios: la primera, la trayectoria de cada uno en el campo mediático. Tiempo Argentino nació en 2010, durante el segundo gobierno kirchnerista, cuando Página/12 ya tenía una posición consolidada gracias al prestigio que había alcanzado con investigaciones de fuerte impacto político, especialmente durante la década del noventa. La segunda divergencia consistió en el lugar que ocuparon en el mercado de medios local. Tiempo Argentino emergió del seno de un multimedio que se encontraba en crecimiento (el Grupo Veintitrés), que hizo implosión tan pronto como finalizó la segunda presidencia de Cristina Fernández de 
Austral Comunicación

Volumen 7 número 2 (diciembre de 2018): 201-228. ISSN 2313-9129

Kirchner, en 2016. Página/12 pasó de ser editado por una empresa de nombre homónimo que solo publicaba este diario a formar parte de un grupo de medios (el Grupo Octubre). ${ }^{5}$

El tercer aspecto para mencionar antes de desarrollar el análisis comparativo remite a los efectos que conllevan las diversas trayectorias de esos medios en la subjetividad de los periodistas más jóvenes que comenzaban a dar sus primeros pasos en el mercado laboral de la prensa gráfica. Veremos que las expectativas depositadas en la inserción en un medio con cierto reconocimiento y prestigio diferían de las que tenían quienes entraban a trabajar en "un diario nuevo". La breve reseña que se presenta a continuación sobre los orígenes de cada medio obedece, precisamente, a esta necesidad de comprender las motivaciones que los periodistas tenían al ingresar en un medio u otro.

El proyecto de Página/12 surgió en la última transición que vivió la Argentina desde un gobierno dictatorial hacia la vida democrática. En ese contexto de regeneración de las instituciones políticas y de las libertades civiles en una sociedad más bien habituada a la alternancia de civiles y militares en el poder, las nuevas circunstancias se manifestaron en la abierta expresión de voces que hasta entonces habían estado acalladas y que encontraron nuevos canales en medios de comunicación que empezaron a florecer.

El diario surgió de la necesidad explícita entre los sectores de izquierda y progresistas de contar con un nuevo medio en el cual se vieran reflejadas sus propias interpretaciones sobre la realidad política y social. Página/12 fue, en este sentido, y al igual que otros medios, hijo de su contexto histórico. Como señalan González \& Constantini (1992):

\begin{abstract}
Página/12 encuentra el hueco repentino que entrega la sociedad argentina sometida al doble escándalo de una represión clandestina llevada más allá de lo humano y el final sin gloria de los grandes proyectos de cambio que apelaban a la imaginación social en favor de "los condenados de la tierra". Era posible ahora que los sectores inspirados por las culturas de rechazo a lo establecido pensaran en la posibilidad de una izquierda en el método retórico que al mismo tiempo disputara racionalmente el mercado lector, generara nuevos lectores modernos y trazara fronteras muy móviles con las diversas actualidades políticas y económicas (p. 12).
\end{abstract}

Así, desde su primera publicación en mayo de 1987, este diario se hizo eco de la demanda de justicia por parte de los organismos de derechos humanos y de su lucha por el esclarecimiento de los crímenes más atroces que se vivieron en el país entre los setenta y principios de los ochenta. En la etapa fundacional fueron convocados periodistas que habían formado parte de las organizaciones revolucionarias de los setenta y que habían sufrido en carne propia la privación de la libertad, la tortura, el exilio y la desaparición forzada de familiares, amigos y compañeros. Este factor contribuyó a dar forma a un medio que, con el tiempo, fue valiéndose de la definición de "diario de los

\footnotetext{
El seguimiento de los dos medios en los cinco años que duró la investigación sirvió de muestra para advertir los rápidos reajustes que se producen en el mapa de medios argentino.
} 
derechos humanos", cuyo espectro de preocupaciones se amplió hacia la vulneración de los derechos de diversas minorías y grupos sociales desaventajados.

A su vez, se consideró el carácter innovador que este diario le imprimió al mundo de la prensa gráfica, no solo por las temáticas que se propuso abordar en un contexto singular del país y de la región, sino también por "asentar" un particular estilo para comunicarse con sus lectores (Bernetti, 1992; González \& Constantini, 1992; Constantini, 1992). No creó ese estilo, que se nutrió de redacciones de revistas que lo antecedieron, como El Periodista y El Porteño, ${ }^{6}$ pero aun así revolucionó a sus competidores de la prensa gráfica diaria. Desde la sala de redacción, se comprendió que no solo las "tapas" $\mathrm{y}$ los titulares -que redundaron en picos de venta-fueron el toque distintivo del diario, sino también otros dos aspectos que, sin duda, se hallaban asociados a los anteriores: la ruptura de la llamada "pirámide invertida" y la investigación periodística.

El ejercicio del nuevo periodismo en Página/12 se plasmó concretamente en los títulos, en la estructura narrativa de las noticias y, hacia la década del noventa, en la práctica de un periodismo de investigación que llevó al diario a "marcar agenda" y a ascender posiciones dentro del campo periodístico local. El diario no solo cambió el estilo de sus competidores, sino que poco a poco también fue fijando la agenda con temáticas que habían sido poco exploradas por el periodismo mainstream, como las mencionadas sobre delitos de lesa humanidad y, más adelante, los escándalos de corrupción que irrumpieron desde la prensa en la política democrática en la década del noventa (Pereyra, 2013).

El período que aquí se aborda, que coincide con el último gobierno kirchnerista, cristalizó el viraje en el posicionamiento del medio respecto al poder político, pues se volvió, a los ojos de periodistas tanto propios como ajenos al diario, un medio menos cuestionador y más afín al oficialismo. Los hechos políticos que tuvieron lugar a partir de la denominada crisis del campo de $2008^{7}$ signaron el vínculo entre los medios y la

\footnotetext{
6 Señala Bernetti (1992), en referencia a la revista El Porteño, que su "tono paródico preanunció el estilo que el diario Página/12 impondrá años más tarde” (p. 6). Respecto a El Periodista, Anguita (2002) planteó que entre sus lectores se hallaba "una clientela politizada, reclutada entre el alfonsinismo aluvional y esperanzado de 1983 y una izquierda inquieta y-como tantas otras veces- sin pertenencia fija" (p. 161). Bernetti (1992) sostuvo que esta publicación vinculó "armoniosamente la posición ideológica de izquierda con la profesionalidad. [En su aparición] es importante examinar la importancia de su diseño gráfico, clave en un diseño periodístico en una época en donde lo visual, la imagen, predomina de manera notoria por el peso que se desprende de las tecnologías audiovisuales [...] La crónica, la investigación y el ensayo periodístico, con una escritura muy ceñida al programa ideológico implícito o explícito de la publicación, son otras de las características" (p. 5).

El episodio conocido como "crisis del campo" se desató con la presentación del gobierno de Cristina Fernández de Kirchner de la Resolución 125, que establecía retenciones móviles a la exportación de granos. Diversos sectores agrarios vinculados con esta actividad manifestaron inmediatamente su rechazo a través de medidas como el lock out patronal y movilizaciones hacia la Plaza de Mayo, gracias a las cuales también sumaron adeptos entre la clase media y alta porteña. En la opinión pública, el conflicto fue interpretado como una lucha entre dos sectores: "el gobierno" y "el campo". Todo esto marcó una nueva etapa en la relación entre el gobierno y los medios de comunicación en la Argentina; los análisis periodísticos coincidieron mayormente con la interpretación de los hechos en términos de enfrentamiento.
} 
política, lo que tornó dificultosa la tarea de rehuir a la dicotomización entre quienes apoyaban al gobierno y quienes se oponían a él. Un año más tarde, la sanción de la Ley de Servicios de Comunicación Audiovisual y los debates que la precedieron reforzaron las disputas del campo político y, centralmente, de los campos mediático y periodístico. A niveles desconocidos en la historia reciente del país, se cristalizaron las divisiones entre los medios y los periodistas que apoyaban al kirchnerismo y quienes se oponían al gobierno que había impulsado esa norma como una de las principales banderas contra la oposición política, representada por una fracción importante de las pantallas y los editoriales de los medios de mayor audiencia. Página/12 no fue, en ese sentido, un "oficialista de la primera hora", pero en esa división, que caló hondo en el periodismo de los últimos nueve años, fue rápidamente encuadrado por sus competidores como cercano al gobierno, en función del despliegue de una línea editorial más bien armónica gubernamentales con la comunicación que pregonaban desde las altas esferas.

Como planteábamos anteriormente, una de las diferencias centrales respecto al caso de Tiempo Argentino residió en la trayectoria de cada matutino en el campo mediático: este diario apareció en el mercado de la prensa gráfica en $2010 .{ }^{8}$ Se ha entrevistado a periodistas que integraron el staff desde su surgimiento; caracterizaron aquella primera etapa del medio como de un profundo desconocimiento de las características editoriales, estilísticas e incluso del nombre propio que los dueños elegirían para el nuevo proyecto. Aun así, en la etapa de reclutamiento, los periodistas pudieron vislumbrar algunos indicadores de la línea editorial de Tiempo Argentino a partir de las entrevistas que tuvieron con sus editores. "Me imagino que les gustó que yo venía trabajando en una investigación sobre la historia del diario Clarín, sobre el tema Noble, ${ }^{9}$ que acá eran temas casi diarios", explicó un periodista cuando analizaba algunos de los motivos que, según él, definieron su contratación en el diario. El hecho de que su experiencia previa en una investigación sobre violación de derechos humanos hubiera repercutido positivamente en su incorporación al staff le brindó una prueba de la proximidad entre su perspectiva y la del diario en lo referente a esta materia.

Los periodistas de Tiempo Argentino recuerdan haber conocido las características del medio a medida que avanzaban en el trabajo de los números cero, las ediciones de prueba realizadas con anterioridad a la salida del diario el 16 de mayo de 2010. A partir de las "reuniones fundacionales" que el staff mantuvo con la dirección periodística, pudieron saber de antemano que el medio se iba a lanzar al mercado con la propuesta de representar "una voz alternativa". Así, se evocaba el objetivo plasmado en el texto de la

\footnotetext{
El primer diario denominado Tiempo Argentino apareció en la década de 1980, en la transición de la dictadura a la democracia. Se editó entre 1982 y 1986, y no sobrevivió más allá de los primeros años de la vida democrática.

9 El "tema Noble" hace referencia a la causa judicial en la que se investigaba si los hijos adoptivos de Ernestina Herrera de Noble -viuda de Roberto Noble, fundador del diario Clarín, y propietaria del Grupo Clarín- eran hijos de desaparecidos durante la última dictadura militar (1976-1983).
} 
Laura Rosenberg

Identificación política y valores profesionales en tensión en la práctica periodística en dos salas de redacción de la ciudad de Buenos Aires

Ley 26.522 de Servicios de Comunicación Audiovisual, conocida como Ley de Medios, que había sido sancionada recientemente y que se proponía pluralizar el acceso de distintos sectores de la sociedad civil a los derechos de comunicación e información. La nueva ley resultaba atractiva para los periodistas que cuestionaban los altos niveles de concentración de la propiedad mediática en el país, donde el Grupo Clarín había alcanzado una posición dominante, con la consecuente homogeneización de las líneas editoriales de los medios de comunicación nacionales y locales.

En el caso de Tiempo Argentino, la apelación a "las mayorías" y a "lo popular" se imbricó con la expectativa de incorporar la pluralidad de voces que la nueva legislación sobre medios audiovisuales manifestaba amparar. De esta manera, la dirección periodística del medio puso en cuestión la objetividad periodística, entendida como la tarea de aportar al lector una única "verdad" sobre los hechos. Gustavo Cirelli, director periodístico desde 2012, sostuvo en una entrevista realizada para esta investigación que con la creación del nuevo diario se habían propuesto "dar la discusión", pues entendía que existen múltiples perspectivas desde las cuales un mismo acontecimiento puede ser analizado. El proyecto tuvo entonces como propósito presentar una "mirada diferente" sobre la nueva etapa que se había abierto en el país con la salida de la crisis, en los albores del kirchnerismo. Sin embargo, a los ojos de muchos periodistas de la redacción, en la práctica el diario se convirtió en "un caballito de batalla del gobierno en su pelea con Clarín".

En igual sentido, periodistas de Página/12 observaron en este diario cierta "miopía" en el tratamiento de hechos políticos y pérdida del tratamiento crítico de los diferentes sucesos, que había caracterizado al matutino nacido en 1987. El apoyo a la normativa que se plasmó tanto en Tiempo Argentino como en Página/12 se hizo extensivo a otras políticas del gobierno kirchnerista en coberturas y columnas editoriales, por lo que ambos medios fueron caratulados desde la oposición como medios oficialistas y sus periodistas como militantes del kirchnerismo. Desde las redacciones, los periodistas adjudicaron a sus jefes parte de la responsabilidad de que su medio resultara calificado de este modo. Al mismo tiempo, marcaban un distanciamiento respecto a los motivos que orientaban las críticas de los medios dominantes.

En el marco de la investigación que desarrollamos, se analizaron las etapas y las características del proceso de socialización laboral de jóvenes periodistas. Como ya se mencionó, en una primera instancia, se indagó sobre las representaciones de los aspirantes a periodistas, sus conocimientos previos sobre estos medios y las expectativas de ingresar en el mundo periodístico desde estas salas de redacción. En consonancia con sus motivaciones, se analizaron las estrategias que implementaron para integrar el staff de estos diarios de distribución nacional. 
Austral Comunicación

Volumen 7 número 2 (diciembre de 2018): 201-228. ISSN 2313-9129

Tanto para los jóvenes redactores de Tiempo Argentino como para los pasantes de Página/12, la posibilidad de ingresar en estos medios representó un punto neurálgico de sus trayectorias profesionales, lo que se tornó evidente al explorar la dimensión emotiva que predominaba en sus recuerdos acerca de la primera etapa de inserción en el mundo periodístico. Ingresar en Página/12 significaba la posibilidad de formarse en un medio en el que publicaban periodistas renombrados, como Horacio Verbitsky, Mario Wainfeld, Osvaldo Bayer o Juan Gelman, entre muchos otros que plasmaban sus columnas semanalmente. Tiempo Argentino, en cambio, representaba, más bien, una de las muy escasas chances que hallaron periodistas jóvenes de acceder a un empleo estable a partir de la gestación de un nuevo medio de prensa en los inicios de su carrera laboral. ${ }^{10}$ Aun así, en los relatos sobre su ingreso también se manifestaron puntos de encuentro con la línea editorial del diario que se estaba gestando.

Las divergencias entre ambos medios, manifiestas en sus respectivas trayectorias en el campo periodístico, repercutieron en las expectativas que en cada caso se habían forjado los jóvenes respecto a la entrada en estas salas de redacción. En Página/12 portaban mayores conocimientos acerca de las características del diario, de su línea editorial y del prestigio con que contaba en virtud de investigaciones periodísticas sobre escándalos de corrupción con un fuerte impacto en el campo político, principalmente en la década del noventa (Pereyra,2013). Los que iniciaron su carrera en este medio se definían como lectores del matutino y en algunos casos hallaban en sus publicaciones los motivos que motorizaron su opción por la carrera periodística. "Cuando era estudiante secundario, el diario que llevaba bajo el brazo era Página/12. Ese era mi diario de referencia", comentó un expasante y actual trabajador del diario. Otro expasante manifestó: "Cuando entré en la carrera mi objetivo último era ser editor de Política de Página/12". Su interés por trabajar en el diario se fundaba no solo en la calidad periodística que destacaba en sus publicaciones, sino también en el carácter pionero del diario en la incorporación de una agenda amplia en materia de derechos humanos y en la afinidad con un enfoque editorial que se orientaba hacia el arco político de la centroizquierda: "Página era como una especie de conjunción, o de unión, o de punto de encuentro entre lo académico, lo progresista, de izquierda y el periodismo de todos los días", refirió ese expasante.

En suma, las expectativas de realizar una pasantía en Página/12 no solo remitían a la intención de aprender las prácticas del oficio en una sala de redacción, sino que se veían incrementadas en función de la proximidad ideológica que los jóvenes manifestaban respecto a la línea editorial del diario. Principalmente, ansiaban ser parte

${ }_{10}$ En el mercado de prensa argentino, lo que tiende a observarse en las últimas décadas, más que la incorporación de nuevos trabajadores, es una reducción de los puestos de trabajo en la mayoría de los medios comerciales. Solo entre 2016 y 2017 se perdieron más de mil puestos, según consigna un informe del Sindicato de Prensa de Buenos Aires (SIPREBA, 2017) 
Laura Rosenberg

Identificación política y valores profesionales en tensión en la práctica periodística en dos salas de redacción de la ciudad de Buenos Aires

de un medio que había abrazado causas políticas, económicas, sociales y culturales con las cuales ellos se habían sentido identificados, las que veían plasmadas entre sus páginas desde su gestación, durante la recuperación de la democracia en Argentina en la década del ochenta. Como veremos más adelante, esta proximidad ideológica no evitó la existencia de conflictos internos en la sala de redacción, asociados al enfoque en función del cual se cubrían noticias de la coyuntura política, económica y social.

Cabe destacar que aquí no nos planteamos hacer un análisis de contenido de las notas periodísticas que compruebe o refute el carácter oficialista de estos medios. Nos propusimos, en cambio, analizar las tensiones manifiestas dentro de las salas de redacción en torno a los efectos que producían esas percepciones sobre la afinidad política de la línea editorial con el kirchnerismo. La preocupación central remitía al modo como la cercanía con el gobierno podía afectar la calidad periodística del producto noticioso y las etapas previas de elaboración de las noticias, en las que ciertos temas se ausentaban de la agenda de estos medios.

En definitiva, aquellas tensiones emanaban de lo que Champagne (1998) definió como "la posición ambigua del periodista", quien está sujeto al mismo tiempo a ideales profesionales y a presiones del poder político y económico. Podemos apelar aquí a la regla del distanciamiento respecto a las fuentes de información (Lemieux, 2010) -en función de la cual los periodistas presentan una voz diferente que no se confunde con la de sus fuentes- para identificar la estrategia que intentan aplicar los periodistas de estos diarios con el objeto de hacer prevalecer los valores profesionales por sobre la identificación político-partidaria.

Ese distanciamiento no exigía una búsqueda de tratamiento "objetivo" de las noticias, sino eludir la obsecuencia con las fuentes oficiales sobre los temas referidos a los gobiernos nacionales, provinciales o municipales de signo kirchnerista en estos diarios. Se proponía, en cambio, efectuar un abordaje crítico sobre todos los hechos noticiables, en cuyo análisis los periodistas no fueran privados de interpelar y cuestionar a los diversos actores políticos y económicos. La tensión entre la identificación política y los valores deontológicos se puede ver graficada en las palabras de un periodista de Página/12:

\footnotetext{
Yo estoy de acuerdo con muchas de las medidas de este gobierno y las defiendo, porque dio respuestas a demandas sociales, políticas y económicas que teníamos desde hace quince años atrás. Pero para mí no son moneda de cambio para el ejercicio de la profesión si le tengo que perdonar a un gobierno todas las sospechas que pueda llegar a tener... ¡Si tengo que ser complaciente con un gobierno porque puso la Asignación Universal por Hijo, váyanse a la mierda! No cuenten conmigo.
}

En el siguiente apartado se analiza esta tensión que sugiere la cita y que da cuenta de las disputas que se desarrollaron cotidianamente entre las directivas relacionadas 
Austral Comunicación

Volumen 7 número 2 (diciembre de 2018): 201-228. ISSN 2313-9129

con la cobertura de los hechos noticiables -observables a partir de la definición y aplicación de los criterios de noticiabilidad- y la defensa de valores profesionales que los periodistas veían amenazados.

\section{Valores profesionales en cuestión: definición y aplicación de los criterios de noticiabilidad, y críticas a la línea editorial}

"Si hacés una encuesta acá, seguramente gane Cristina", dijo en una oportunidad un editor de Tiempo Argentino, "pero eso no significa que seamos ultra K". ${ }^{11}$ Con estas palabras, diferenció "la redacción" de quienes ocupaban la dirección del diario y "bajaban línea" sobre el tratamiento de los temas. Incluso en las paredes de las salas de redacción de ambos diarios se ilustraba esa afinidad política con el kirchnerismo, que se podía observar en distintos carteles y afiches, así como el rechazo a la figura de Mauricio Macri ${ }^{12}$ y el partido que lidera. Pero más allá de este primer panorama que un observador encontraba al entrar a estos espacios de trabajo, veremos que esa proximidad política es puesta en cuestión a la hora de desempeñarse profesionalmente.

A partir de las percepciones que los propios integrantes de Tiempo Argentino daban sobre el medio, se pudo visualizar una adscripción identitaria que se establece a partir de una diferenciación entre los periodistas más críticos de la orientación ideológica del diario y quienes ellos denominaban los gurkha o talibanes: directores, editores o redactores que adherían acríticamente al kirchnerismo. En esta definición, la línea editorial de este medio aparecía indisociable de la agenda del Frente para la Victoria, partido político que había surgido con anterioridad al diario y se encontraba en el poder en aquel tiempo. Había en Tiempo Argentino redactores y editores que adjudicaban a los talibanes un fanatismo ideológico y la responsabilidad de que este medio fuera visto entre sus competidores, pero también desde el arco político y social en general, como "un medio oficialista".

El mismo calificativo fue asignado a Página/12 por sus detractores dentro y fuera del campo periodístico, no obstante las críticas que se hacían sentir dentro de la sala de redacción y que generaban que, por ejemplo, un redactor protestara: “ ¿Hay que poner 'Viva Cristina' y hay que firmarlo encima?". O que una redactora se quejara de "lo tuerta" que estaba la sección Economía y de que Sociedad estuviera "mucho más light" que hacía unos años, cuando se caracterizaba por publicar "notas de denuncia en unas páginas que los medios en general ocupan con noticias blandas.

\footnotetext{
${ }^{11}$ La expresión ultra $K$ se refiere a quienes hacen una defensa acérrima del kirchnerismo y de las políticas de su gobierno.

12 Mauricio Macri fue electo presidente en 2015, al triunfar la fórmula presidencial del frente político Cambiemos, principal fuerza opositora al kirchnerista Frente para la Victoria. El propio nombre de Cambiemos remitía a la intención de gestar una alternativa política tras doce años de gobierno del kirchnerismo.
} 
Laura Rosenberg

Identificación política y valores profesionales en tensión en la práctica periodística en dos salas de redacción de la ciudad de Buenos Aires

Estas críticas se hicieron explícitas tanto en instancias de cobertura como de edición de las noticias, y en discusiones concernientes a los criterios de selección de los acontecimientos noticiables. En ese sentido, la indagación sobre los criterios de noticiabilidad permitió comprender tanto la organización de la rutina de trabajo como las situaciones de conflicto generadas en torno a la línea editorial del medio.

Los criterios de noticiabilidad pueden definirse como valores noticia (Wolf, 1987) que facilitan la rutinización del trabajo cotidiano en las organizaciones periodísticas, al constituirse en esquemas interpretativos para identificar aquellos acontecimientos que pueden ser convertidos en noticia. En los hechos funcionan como convenciones (Becker, 2006) a partir de las cuales se estandarizan los modos de realizar la actividad periodística, lo que allana así la coordinación del trabajo colectivo. Conforman, entonces, reglas prácticas que organizan el trabajo periodístico; implican la internalización, por parte de los integrantes del campo, de un conjunto de valoraciones compartidas acerca de qué se entiende por noticia. Manuales de estilo y guías para el trabajo que circulan en el sector periodístico dan cuenta de que algunos criterios, como los relativos a la novedad y a la cercanía geográfica y social de los involucrados, son comúnmente aceptados y compartidos, independientemente de cuál sea el medio en que se trabaje. Existen otros, en cambio, que se identifican con los medios en cuestión y que esperan responder a la demanda de un tipo específico de lector. En función de lo observado, se analizó que el carácter político que reviste la organización del trabajo en la sala de redacción se puede advertir desde el momento en que se define qué acontecimientos son noticiables, y no solo al determinar el enfoque para su abordaje.

El nivel de internalización y naturalización de los criterios de noticiabilidad entre los periodistas no los vuelve, no obstante, incuestionables. En la medida en que el trabajo en una redacción se desarrolla en el marco del esquema verticalista propio de las empresas periodísticas, el establecimiento de estos criterios no ha sido resultado de acuerdos entre el conjunto de los miembros que conforman ese espacio de trabajo. Por el contrario, quienes siguen estas reglas prácticas difícilmente puedan modificarlas. Entonces, si bien es cierto que los valores noticia permiten rutinizar la labor periodística sobre "lo inesperado", ello no significa que este proceso esté exento de conflictos. Los criterios compartidos a fin de que el diario salga todos los días han sido impuestos "desde arriba" y llevan el sello de una línea editorial con la cual muchos periodistas disienten. Por ello, solo en raras ocasiones -que motivan distintos tipos de sanciones informales- los periodistas se niegan rotundamente a cubrir un tema; es más probable que hagan el trabajo a desgano y exijan "no firmar" la nota en cuestión. Un redactor de la sección Política de Tiempo Argentino justificó esta práctica en función de "la potestad del redactor" sobre su firma. Respecto a esta cuestión, un editor del mismo diario agregó: 
Es la última muralla que tiene el periodista, y yo lo respeto. Nadie sería tan canalla de pedir una firma a un chivo, gracias que lo escribe. Existen los límites propios: un periodista, ¿siempre hace lo que le decís? Todos tenemos límites, un equis porcentaje de chivos por día lo tolero, pero si son muchos por día, te pregunto: “¿Dónde está la puerta?”, y me fui...

Los periodistas que "no quieren firmar nada" son mayormente críticos a la línea editorial que dispone que un determinado tema -a sus ojos, irrelevante o "mal enfocado"- deba ser tratado como noticia. Generalmente deciden: "Yo la nota te la escribo, pero no te la firmo". Si bien se trata de un derecho asumido en el campo periodístico, la decisión de no firmar motivó rispideces entre editores y redactores de los diarios estudiados.

A continuación, señalamos los criterios identificados en el trabajo cotidiano en las salas de redacción que nos permitieron pensar en los acuerdos y conflictos que se suscitan entre quienes determinan qué hechos hay que cubrir y quienes elaboran las noticias. Esos criterios no responden necesariamente a la explícita distribución de roles evidenciable en el seno de toda organización periodística.

\section{1) La novedad y la actualidad}

El criterio de novedad se basa en la búsqueda y la selección de acontecimientos excepcionales que quiebran un estado de "normalidad" y se vuelven susceptibles de ser convertidos en noticias. De este modo, un hecho puede considerarse noticiable si da cuenta de nuevos sucesos sobre los cuales existe poca o nula información. Hay ciertos hechos ruptura (Rodrigo Alsina, 1993), cuya inclusión en la agenda mediática resulta incuestionable para los periodistas de los medios informativos: a nivel local, se pueden citar diversos episodios, como el triunfo de Cristina Fernández de Kirchner, la muerte de Néstor Kirchner o la llamada "tragedia de Once". ${ }^{13}$ Sobre la base del criterio de actualidad, los periodistas orientan el tratamiento de hechos que son informados durante la coyuntura y que son actualizados con nueva información.

Según un joven redactor de Tiempo Argentino, para definir la noticia "uno piensa en la novedad, y si hay algún dato". Otra joven redactora del mismo diario planteaba, en cambio, que este criterio carecía de toda especificidad. En la práctica, no todo acontecimiento "novedoso" es considerado noticiable. "Los de arriba" exigían algo más: "que haya un título", algo que dé cuenta de que el hecho es excepcional por el carácter novedoso de la información que aporta y sirva como "excusa" para que la nota sea publicable:

13 "La tragedia de Once" hace referencia a un accidente ferroviario ocurrido en 2012 en la estación Plaza Once de la línea Sarmiento, en la ciudad de Buenos Aires, en el que fallecieron cincuenta y una personas. 
Si una nota no tiene título, no te la publican. Si te hablo de un tema, como una manifestación por violencia de género, me preguntan: “¿Cuántas putas fueron?”. ¡Entre [el jefe de redacción] y yo hay un choque de civilizaciones!

Este "choque de civilizaciones" graficó la frecuente puesta en cuestión de este criterio de noticiabilidad, que para los periodistas más críticos llevaba muchas veces a "caer" en hacer un diario de baja calidad, menos analítico y más sensacionalista.

\section{2) La cercanía geográfica y social de los afectados/involucrados}

La cercanía geográfica y social también forma parte del abecé de criterios para valorar un acontecimiento como noticia. Investigaciones sobre la producción de noticias (newsmaking), como las realizadas por Gaye Tuchman (1983) o Herbert Gans (2004), han destacado que la cercanía de las fuentes de información resulta un factor clave en el establecimiento de la agenda temática de los medios. Por el contrario, la lejanía geográfica puede operar como una barrera a la hora de que el medio se interese por la noticiabilidad de un determinado suceso. De la misma forma, la proximidad social con las fuentes acerca a los medios a ciertos hechos y no a otros. Según Gans (2004), esta cuestión refiere, en parte, al lugar que ocupan los periodistas en la sociedad: las clases medias y altas presentan menores inconvenientes para alcanzar la atención de los medios. Ello contrasta con la situación de los sectores populares, que tienden a hacer su aparición en los medios desde el prisma de las otras clases sociales, tal como consigna Champagne (2007). En consonancia con esta perspectiva, Tuchman (1983) caracteriza la noticia como un "recurso social estratificado" y señala que los medios de comunicación resultan más accesibles a ciertos grupos y movimientos sociales y políticos que a otros (p. 147).

Página/12 y Tiempo Argentino surgieron en el campo periodístico con la propuesta de dar lugar a voces que en los medios de prensa tradicionales no tenían resonancia. Y, sin embargo, el día a día de diarios cuyo epicentro se encuentra en la ciudad de Buenos Aires dificulta el tratamiento de cuestiones que tengan lugar fuera del área metropolitana. La limitada disponibilidad de recursos y de viáticos que estas empresas periodísticas brindan a sus periodistas para que puedan desplazarse y realizar sus coberturas también opera en favor de una centralización geográfica de la producción noticiosa en las grandes ciudades; específicamente, en Buenos Aires. Así, un expasante de Página/12, oriundo de una localidad del Gran Buenos Aires, que estaba habituado a trabajar temas sobre el conurbano bonaerense antes de ingresar en el diario, recordó que allí le habían "rebotado" muchas notas "porque Página es un diario muy porteño". Teniendo en cuenta que se trata de la ciudad más rica de la Argentina, la centralización geográfica del trabajo que realizan los periodistas pone en jaque los relatos fundacionales de estos diarios, porque se privilegian en su foco las problemáticas asociadas a 
las clases medias urbanas. En este sentido, uno de los factores que había motorizado el interés de los periodistas más jóvenes por trabajar en Página/12 -su amplia cobertura temática en derechos sociales de los sectores desaventajados- aparecía desdibujado en la rutina cotidiana ante las dificultades de cubrir problemáticas que afectaran a los sectores que suelen tener menor llegada a los medios de comunicación comerciales.

De igual manera, aunque Tiempo Argentino ubicaba a su lector entre "las mayorías" y su tendencia como "generalista y popular", sus periodistas evaluaron que se priorizaba la atención sobre hechos vinculados con las clases medias y altas urbanas, y relegaba a un lugar marginal la realidad de los sectores tradicionalmente postergados. Los periodistas más críticos consideraron una fuerte impronta clasista por la cual en Tiempo Argentino se tendió a asignar mayor seguimiento y jerarquización en la agenda a ciertos hechos que afectaban a la clases medias y altas urbanas, en contraste con otros que involucraban a los sectores populares: "Seguimos a la gente rica. Después nos quejamos de que perdemos lectores”, “ipor qué el diario tendría que hablar de un chico que se accidentó en Disney y no de la salud de otros nenes que viven acá?”. Para los periodistas más críticos, el criterio de cercanía geográfica y social reveló una contradicción entre "el discurso progre de los de arriba" -manifiesto en los editoriales publicados y en los discursos pronunciados durante las reuniones de staff, en las que se remarcaba el interés del medio por las problemáticas de los sectores más desfavorecidos y la necesidad de promover la inclusión social- y la definición de una agenda más próxima a lectores de clase media y alta.

En el trabajo cotidiano, lo anterior se tradujo en una cobertura mayor sobre hechos que se desarrollaron en los barrios céntricos y de la clase media urbana, que relegaba a un segundo plano lo ocurrido en otras zonas de la ciudad y del país. Esto se tornó habitual en los diarios argentinos que poseen distribución nacional, pero cuya cobertura se concentra mayormente en la región donde se hallan ubicadas las salas de redacción.

\section{3) Temas "de agenda"}

Una de las premisas centrales de la teoría de la agenda setting desarrollada por McCombs \& Shaw (1972) destaca que los medios de comunicación fijan la agenda de temas que revisten mayor relevancia para la sociedad y merecen ser objeto de debate. En su incidencia sobre la agenda pública, los medios cumplen un rol central en la construcción de la realidad social y en la jerarquización de la información que producen.

En principio, resultaría un planteo tautológico decir que un suceso es noticiable porque ya ha sido definido como tal. Sin embargo, no se puede pensar en los medios como instituciones monolíticas y cerradas que toman aisladamente sus decisiones acerca de lo noticiable. Por el contrario, en un espacio mediático como el argentino, que cuenta con medios de comunicación con estructuras muy diversas entre sí, no se 
Laura Rosenberg

Identificación política y valores profesionales en tensión en la práctica periodística en dos salas de redacción de la ciudad de Buenos Aires

puede producir noticias desde una suerte de vacío informacional. Los capitales que se requieren para hacer el trabajo, así como los lectores y las audiencias, están distribuidos desigualmente. Esta disparidad en los recursos, las audiencias y el timing con el que opera cada medio promueve una circularidad en el proceso de reproducción de la agenda mediática palpable en la lectura de los titulares de prensa en los programas radiales matutinos y los televisores encendidos a toda hora en agencias de noticias y redacciones de los diarios. Por su parte, los portales de Internet también han irrumpido en el establecimiento de la agenda mediática.

En este sentido, hay que considerar que no solo los distintos medios ejercen diferente peso en la fijación de la agenda, sino que ellos mismos también son parte de esa agenda pública sobre la cual sus pares tienen injerencia. En los medios resuena el impacto de "los temas del día", que se han instalado y vuelven a ser retomados hasta que culmina la jornada. El imperativo es que, si una noticia ha sido publicada por la competencia, entonces el propio medio también debe publicarla, cuestión que Boczkowski (2010) ha identificado en la producción de las noticias en las salas de redacción de clarin.com y lanacion.com, dando cuenta de las crecientes prácticas de imitación y homogeneización de los contenidos publicados en los distintos medios de comunicación.

Esas prácticas también se pueden advertir en la gráfica: no solo los temas que abordan Clarín o La Nación (diarios con mayor tirada) son susceptibles de ser incluidos en la agenda de Tiempo Argentino o de Página/12, sino también aquellos que "hacen explotar las redes sociales" o "lo que sale en la tele". Esto lo sugería un redactor de Policiales de Tiempo Argentino, al conversar acerca de cómo se seleccionaban, entre cientos de casos, aquellos de niños y niñas desaparecidos que se abordarían como noticia. El entrevistado indicó que "la gente quiere leer en el diario lo que ve en la tele". En la misma línea se inscribe la explicación del editor de Sociedad del mismo diario, respecto a la cobertura del caso de un niño accidentado en Disney: "Si el tema sale en muchos lados, hay que seguirlo".

En el caso de Página/12, los periodistas señalaban el contraste que percibían entre las secciones que tienen mucha producción propia (como Economía o Espectáculos), y secciones donde cada vez predomina más la práctica de lo que se designa en jerga como "cortar cables" (Política y Sociedad). En este sentido, se escandalizaba un pasante que había llevado una propuesta de nota a sus editores, quienes la desestimaron diciéndole: "Pero eso no salió en los cables".

Teniendo en cuenta lo anterior, consideramos que la premisa de la teoría de la agenda setting funciona, en la práctica, como otro criterio de noticiabilidad. "Hay que seguir" un acontecimiento porque otros medios ya lo han hecho. Los medios influencian en la agenda pública imponiendo su propia agenda; pero en este proceso no son ajenos a la de sus competidores, y los temas que estos han considerado que merecen 
ser incluidos también tendrán su injerencia en la selección de otros integrantes del espacio mediático.

De este modo, cuando un tema está instalado en varios medios, resulta "evidente" que hay que tratarlo. La puesta en cuestión de esta "evidencia" hace reflexionar a los periodistas acerca de los motivos que los llevan al tratamiento de ciertas noticias cuando esta actividad tiene a la homogeneización de los contenidos como su consecuencia más directa. Al respecto, Bourdieu (1997) ha planteado que, si bien el campo periodístico es un mundo fragmentado, en el que existen conflictos, competencias y hostilidades, es precisamente la propia lógica de la competencia la que lleva a una uniformación de los contenidos. El hecho de que los informadores se informen a través de otros informadores, quienes les indican qué es importante y qué "merece ser transmitido", se puede describir como "un juego de espejos que se reflejan mutuamente" (p. 32), un "mecanismo de circulación circular por el cual los periodistas se leen mutuamente, se ven mutuamente, se encuentran constantemente en unos debates en los que siempre aparecen las mismas caras" (p. 34). Para el autor, el efecto inmediato de este proceso es una situación de "enclaustramiento, de aislamiento mental" en la cual la censura se torna eficaz.

Parte de la controversia que se jugaba en los diarios no solo se daba en torno al sentido impuesto a los acontecimientos, sino que también se plasmó en el cuestionamiento sobre los criterios mismos de selección y jerarquización de los temas noticiables. Es decir, la discusión con "los medios hegemónicos" se produjo mediante el planteo de otra visión sobre ciertos hechos y además disputando el poder de establecer los temas de los que "hay que hablar", a través de la denuncia de otras cuestiones que eventualmente pueden ser "levantadas" por esos medios de mayor tirada (algo que se percibe como muestra del éxito de la jugada). La cuestión, en definitiva, interesa más a "los de arriba" -en la medida que provoca alteraciones en la posición relativa del medio frente a sus competidores- pero afecta al trabajo cotidiano en las redacciones, llevando a que el interés por un hecho noticiable se confunda con la crítica a las interpretaciones de otros medios sobre el mismo acontecimiento.

\section{4) "El diario de los derechos humanos"}

La transición democrática que contextualizó la aparición de Página/12 en el campo periodístico selló en el diario una impronta que mantiene vigencia, que consagró al medio como "el diario de los derechos humanos". Página/12 no existía cuando se realizó el "Juicio a las Juntas" ${ }^{4}$ durante la presidencia de Raúl Alfonsín, pero desde sus

\footnotetext{
${ }^{14}$ El “Juicio a las Juntas" es el proceso realizado en el año 1985 por iniciativa del presidente Raúl Alfonsín contra los integrantes de las juntas militares de la última dictadura militar, que fueron condenados por violación sistemática de los derechos humanos.
} 
Laura Rosenberg

Identificación política y valores profesionales en tensión en la práctica periodística en dos salas de redacción de la ciudad de Buenos Aires

inicios se hizo eco de las denuncias impulsadas por diversas organizaciones de derechos humanos para el esclarecimiento de los crímenes cometidos durante la última dictadura militar en la Argentina (1976-1983). La tematización y jerarquización que hizo Página/12 sobre problemáticas asociadas a los derechos humanos no se restringieron a la sección Política, sino que se extendieron a las distintas secciones del diario, y se articularon con las esferas económica, social y cultural, tanto en el plano local como en el internacional. El editor de Sociedad explicó cómo el diario "marcó agenda" en ciertos temas que anteriormente no aparecían en los medios:

¿Cómo alguien se iba a imaginar que en la Argentina dos personas del mismo sexo se podían casar? ¡Que alguien esté proponiendo eso y haciendo una campaña para eso era un delirio! Bueno, Página/12 la hizo la tapa del diario. Un año y pico después fue ley. Y como esos temas, Página/12 marcó agenda en muchos otros temas, no solamente políticos y económicos, sino también sociales.

Este aspecto distintivo del diario, que hizo de la temática de los derechos humanos un criterio de noticiabilidad en sí mismo, fue el que generó mayor consenso entre sus integrantes y el que los identificó con el medio en el que se desempeñan como periodistas. Resultaba uno de los motivos por los cuales los jóvenes periodistas ansiaban formar parte de la redacción del diario.

Tiempo Argentino retomó en su línea editorial la propuesta de Página/12. La dirección manifestó su intención de aportar a la instalación de la agenda de derechos humanos en los medios. Sin embargo, según veíamos anteriormente, se contradecía, por ejemplo, cuando en sus páginas se jerarquizaban problemáticas relacionadas con las clases medias urbanas por encima del acceso a la salud o la vivienda de otros sectores de la población.

\title{
5) “Lo K" y "lo anti-K"
}

Rodrigo Alsina (1993) plantea:

\begin{abstract}
No todos los sujetos sociales son competentes para producir hechos-ruptura y hechos-noticia [ni] todos los hechos-ruptura y hechos-noticia tienen el mismo significado desde el punto de vista del statu quo [...] El sistema político recibe una atención privilegiada por parte de los mass media: entre los sujetos sociales productores de hechos-ruptura y de hechos-noticia emerge un sujeto privilegiado -la clase política- depositario de la función de continuidad y mantenimiento del orden (p. 123).
\end{abstract}

Página/12 y Tiempo Argentino no son una excepción. Si bien se trata de diarios "generalistas", los temas políticos y la sección Política han sido jerarquizados en ambos, y las publicaciones diarias de las secciones El País y Argentina, respectivamente -y, en el caso de Página/12, también la cantidad de periodistas asignados a ellas- superan al resto de las secciones. 
A medida que ambos diarios mostraban su afinidad política con el gobierno kirchnerista, dentro de las redacciones crecían los reproches por un tratamiento que consideraban excesivamente benévolo hacia el gobierno nacional y sus aliados, en contraste con las críticas orientadas a buena parte del arco opositor, entre quienes se incluían "los medios hegemónicos". En comparación con los criterios de noticiabilidad señalados anteriormente, este es el que generó mayores controversias en las salas de redacción.

Lo que redactores y editores de Tiempo Argentino ponían en cuestión era el modo como se abordaban las coberturas; esto parecía ser algo que se imponía "desde arriba", sobre lo que difícilmente podían interferir. Para los periodistas más críticos, "la pericia con el gobierno" o una "buena lectura política" no eran prácticas que "los de arriba" realizaran con asiduidad. En cambio, aseguraban que estos desdeñaban los códigos del trabajo periodístico que exigen el chequeo y el contraste de la información con distintas fuentes, priorizando la afinidad política sobre la actitud profesional. Dentro de las salas de redacción de ambos medios, se percibía que los riesgos de incurrir en faltas profesionales eran mayores cuando la afinidad política se veía muy reflejada en el producto. Temas que en otro contexto resultaban noticiables para un diario como Página/12 -y que resultaban centrales en la propuesta editorial que el diario presentó a sus lectores cuando apareció en el mercado- ahora se ausentaban de la agenda. Según el parecer de los periodistas, esas coberturas podían afectar la imagen del gobierno. Un expasante del diario señaló lo siguiente:

Quizá como desafío particular de Página es que el diario estaba en un momento más oficialista que hace tres o cuatro años atrás, entonces había temas que se habían dejado de seguir y había cosas que ya eran como más edulcoradas [...] hay ciertos temas que el diario seguía mucho entre el 2001 y el 2004, como pobreza, violencia policial, conflictos sociales, que, conforme más el diario se convirtió en una cosa de vocero del gobierno, se dejaron de seguir.

La crítica a la línea editorial se personalizó en "la dirección" o en "los de arriba" y se enmarcó en la valoración que los periodistas tenían sobre su trabajo. "Hacer bien el trabajo" "ser serio" o "profesional" no tenía que ver con una pretensión de objetividad o de apoliticidad en el trabajo periodístico. Si para ellos no era posible hacer "periodismo independiente", su labor tampoco debía servir como "caballito de batalla" del gobierno.

Una particular muestra de esta percepción se pudo notar una tarde en la sala de redacción de Tiempo Argentino, dadas las repercusiones que había recibido la publicación de una nota de opinión que llevaba la firma de una periodista del diario. Este hecho representó un contraejemplo de lo que significa para los periodistas distinguirse positivamente en su práctica laboral. La nota seguía el formato de carta, estaba dirigida a Cristina Fernández de Kirchner y relataba un encuentro casual que la redactora en cuestión había tenido con la presidenta, durante el cual le había contado a la manda- 
taria que había soñado con su marido Néstor Kirchner, ya fallecido. La nota contenía una fuerte carga emotiva y fue tan criticada en diversos portales de Internet y redes sociales que en la sala de redacción se comentaba: “Twitter es un festín”, y se rumoreaba el tema entre risas e indignación. Se conversaba acerca de los mensajes que aparecían en Twitter, que cada uno podía leer desde su computadora. La preocupación entre los periodistas no solo se manifestaba a través de sus críticas a la excesiva demostración de afecto y de afinidad política con la presidenta y el expresidente que se había publicado en el medio en el que ellos trabajaban -que, en última instancia, era solo un elemento más entre tantos otros que hacían de Tiempo Argentino "un diario oficialista"-, sino también por el hecho de que se había quebrado otra de las reglas de juego del mundo periodístico, que se basa en el recurso a fuentes de información fidedignas; fundamentalmente, con anclaje en la realidad social y no en el mundo onírico. Esto redunda en la calidad en la producción de las noticias, como mencionaban en la redacción: “ ¿Cómo hace Szpolski ${ }^{15}$ para hablar de periodismo de calidad después de esto?”, señalaba una periodista. Otra redactora sostenía al respecto: “ $\mathrm{Me}$ parece preocupante que se publique cualquier cosa! ¡Esto no es un blog! A ver, ¿cómo es? Si mañana sueño con La Cámpora, ${ }^{16}$ ¿me lo publican también?”.

La situación dio cuenta de las objeciones al criterio editorial de la dirección del diario y la preocupación por los valores profesionales que se ponían en juego: ¿es válido recurrir a cualquier material, en este caso un sueño, para hacer una crónica? ¿Cómo se hace un aporte, cómo se distinguen el medio y el periodista en un sentido positivo? El debate apuntaba a que los recursos a los que había apelado la periodista remitían pura y exclusivamente a la dimensión subjetiva, que en ningún momento confrontó con elementos fácticos que pudieran ser interpretados y contrastados por sus colegas y por los lectores. A ojos de aquellos, el texto no encuadraba ni siquiera en los estándares propios de una nota de opinión.

Episodios como estos eran los que llevaban a los periodistas a reflexionar sobre la posibilidad de hacer "buen periodismo" desde los medios comerciales. Además, a partir de esas situaciones se hacía evidente para ellos la diferenciación entre su condición de trabajadores de un medio y su identificación con la línea editorial de este. En ese sentido, los periodistas destacaron la diferencia entre "cómo se nos ve de afuera" y cómo se concebían a sí mismos: "Yo te aseguro que estando en Página/12 te volvés más 'anti K' y estando en Clarín te volvés 'ultra K. ¡Te lo aseguro! Porque te das cuenta de la mugre que hay adentro, y entonces te querés separar de eso".

\footnotetext{
15 Sergio Szpolski fue el dueño del Grupo Veintitrés, que editó Tiempo Argentino desde 2010 hasta 2015. El diario fue discontinuado hacia inicios de 2016 por decisión de los propietarios del grupo, al cual disolvieron en el mismo período. En la actualidad, Tiempo Argentino es editado por la cooperativa Por Más Tiempo, creada tras varios meses de lock out y abandono de los medios del Grupo Veintitrés por parte de sus dueños.

${ }^{16}$ La Cámpora es una agrupación política juvenil kirchnerista fundada en 2006 (http://www.lacampora.org/).
} 
Lo anterior muestra el posicionamiento que adoptaron los periodistas de la redacción frente a los vaivenes político-ideológicos del medio donde trabajaban. Las críticas a la línea editorial promovían en ellos la intención de separarse, en términos identitarios, de su lugar de trabajo: ellos no son "el diario", sino "laburantes". Esta diferenciación toma recursos de la deontología profesional, que exige que la identidad política no cerque la actitud crítica de los periodistas ante el poder.

Las disputas internas en la sala de redacción en torno a la definición y aplicación de los criterios de noticiabilidad trazaron diferencias entre dos grupos dentro de las organizaciones periodísticas, atravesados por los roles que desempeñaban quienes definían la línea editorial y quienes cubrían las noticias de acuerdo con el enfoque impuesto "desde arriba". En la descripción de esas discusiones y la conformación de estos dos grandes grupos también se pudo identificar la defensa de valores que los periodistas destacaban como orientadores de su práctica laboral. En este sentido, la identidad profesional aparecía asociada al análisis crítico de los acontecimientos y al distanciamiento respecto a las fuentes. Eso no significa que los periodistas adscribieran a posturas que exigieran un tratamiento neutral de las noticias en términos políticos. Por el contrario, también se destaca el compromiso político entre las prácticas del oficio, entendido en relación con el deber de representar en los medios más la voz de los sectores más desaventajados que la de los sectores del poder político y económico.

\section{Conclusión}

En este artículo nos propusimos indagar sobre las tensiones que se suscitaron en el interior de dos salas de redacción entre la identificación político-partidaria de sus integrantes y la deontología de la profesión periodística. Se observó que las discusiones y los conflictos desarrollados en torno a la definición y cobertura de los temas noticiables brindaban indicadores acerca del imaginario que los periodistas construyen sobre su trabajo y sobre los valores y reglas que, estiman, deberían regularlo.

Partimos de la definición de la identidad como un proceso en permanente construcción, que no es posible comprender si no se atiende a las situaciones de interacción en las cuales las personas forjan percepciones sobre sí mismas y sobre los demás. A partir de esta concepción, consideramos posible analizar las tensiones - no contradicciones- que encierra el proceso de conformación de la identidad profesional de los periodistas.

Analizamos los factores asociados a la conformación identitaria de los periodistas en dos tramos de la carrera laboral de los más jóvenes en las salas de redacción. El primero de ellos se relaciona con la etapa de ingreso en el diario, en la cual se dio cuenta de las expectativas que estos periodistas tenían y los motivos que los orientaban a desear entrar en estos medios. Entre ellos, se destacó la afinidad con la línea editorial 
Laura Rosenberg

Identificación política y valores profesionales en tensión en la práctica periodística en dos salas de redacción de la ciudad de Buenos Aires

de ambos diarios o con la propuesta que la dirección periodística había presentado a sus lectores desde el momento de la gestación del medio. Los periodistas compartían el interés por temáticas de derechos humanos y problemáticas asociadas a la situación de los sectores populares, que generalmente habían sido excluidas de la agenda de los medios tradicionales.

El contexto político en el cual los gobiernos kirchneristas se pronunciaron en favor de atender intereses y demandas de los sectores más postergados de la sociedad promovió la aproximación al partido gobernante por parte de periodistas y medios que se sentían comprometidos política y socialmente con esas causas. En este punto, convergían la identificación del periodista como profesional vinculado con la realidad social y la línea editorial de estos medios, que se manifestaba en igual sentido. En este aspecto, parecía no haber conflictos entre los valores profesionales y el posicionamiento político que asumían estos diarios en un contexto signado por la polarización del campo periodístico.

Sin embargo, en la segunda instancia de conformación identitaria que se analizó, se problematizó el lugar asignado a la toma de posición política en las prácticas cotidianas de producción de las noticias. Se puso en cuestión, entonces, el papel que jugaba la identidad político-partidaria de los miembros de las redacciones a la hora desempeñarse como periodistas. Esto se debía a los conflictos que se asociaban a las directivas impuestas "desde arriba", que para los periodistas más críticos redundaban en una sumisión de los valores profesionales a la lógica política. Se observó así el sentido que adquiere realizar un análisis sobre los procesos de identificación, atento a las situaciones de interacción que pueden revelar cambios en los modos como las personas se perciben a sí mismos y a los demás en función del contexto.

$\mathrm{Al}$ indagar sobre las prácticas cotidianas de trabajo en las redacciones, se planteó que, en ciertas ocasiones, los periodistas pretendían aplicar la regla del distanciamiento respecto a las fuentes oficiales. Incluso quienes se manifestaban abiertamente a favor del kirchnerismo cuestionaban que el medio donde trabajaban asumiera un rol de "vocero del oficialismo". El interrogante que se planteaba entonces era: ¿̇se puede hacer periodismo desde medios "oficialistas"? En otras ocasiones, por el contrario, los periodistas marcaban que la línea editorial quebraba su compromiso con las causas políticas y sociales que decía defender al privilegiar en la agenda cuestiones que afectaban centralmente a las clases medias y altas urbanas, excluyendo coberturas sobre el conflicto social y la pobreza.

Para adentrarnos en estas tensiones propias del trabajo cotidiano en las redacciones, se desarrolló una cuestión escasamente abordada en los estudios sobre el periodismo, que remite a la definición y aplicación de los criterios de noticiabilidad y el modo como estas prácticas contribuyen a definir la identidad profesional de los periodistas. 
Austral Comunicación

Volumen 7 número 2 (diciembre de 2018): 201-228. ISSN 2313-9129

Se destacó que, si bien se trata de normas prácticas compartidas por los integrantes de las organizaciones periodísticas, no son resultado de consensos, sino que condensan las directivas de los actores que juegan un rol jerárquico en las empresas periodísticas. En función de los conflictos planteados en relación con la definición y aplicación de los criterios de noticiabilidad, los periodistas enunciaron las pautas que, a su entender, deben regular su práctica, cuya implementación muchas veces se vio afectada por las presiones propias de sectores del poder político y económico.

En suma, a partir del abordaje etnográfico de la problemática formulada, se identificaron tres reglas centrales, a saber: realizar un análisis crítico sobre los acontecimientos, mantener un distanciamiento respecto a las fuentes de información y preservar el compromiso político del ejercicio de la profesión sin que ello signifique supeditar la propia actividad a los lineamientos de un movimiento o partido político.

\section{Referencias}

Abbott, A. (1993). The Sociology of Work and Occupations. Annual Review of Sociology, $19,187-209$.

Altheide, D. (1984). Creating Reality: How TV News distorts Events. Beverly Hills: Sage. Anguita, E. (2002). Grandes hermanos. Alianzas y negocios ocultos de los dueños de la información. Buenos Aires: Colihue.

Bauman, Z. \& May, T. (2007). Pensando sociológicamente. Buenos Aires: Nueva Visión.

Becker, H. (2006). Los mundos del arte. Bernal: Universidad Nacional de Quilmes.

Becker, H. (2009). Outsiders. Buenos Aires: Siglo XXI.

Becker, H. \& Strauss, A. (1956). Careers, Personality, and Adult Socialization. American Journal of Sociology, 62(3), 253-263.

Becker, H., Geer, B., Hughes, E. \& Strauss, A. (1961). Boys in White: Student Culture in Medical School. Chicago: University of Chicago Press.

Bernetti, J. L. (1992). Después del Proceso: entre la monotonía y la ruptura. Medios y enteros, 2(2).

Boczkowski, P. (2010). News at work: Imitation in an Age of Information Abundance. Chicago: University of Chicago Press.

Bourdieu, P. (1997). Sobre la televisión. Barcelona: Anagrama.

Champagne, P. (1998). La doble dependencia. Algunas observaciones sobre las relaciones entre los campos político, económico y periodístico. En Gauthier, G., Gossellin, A. \& Mouchon, J. (comps). Comunicación y política (pp. 237-254). Barcelona: Gedisa.

Champagne, P. (2007). La visión mediática. En Bourdieu, P. (dir.). La miseria del mundo (pp. 51-63). Buenos Aires: Fondo de Cultura Económica.

Constantini, M. (1992). Un mito diario. En González, H. \& Costantini, M. (1992). 
La realidad satírica: Doce hipótesis sobre Página/12 (pp. 131-137). Buenos Aires: Paradiso Ediciones.

Epstein, E. (2000). News from Nowhere: Television and the News. Chicago: I. R. Dee. Gans, H. (2004). Deciding what's news. Evanston: Northwestern University Press.

Geer, B. (ed.) (1972). Learning to work. Beverly Hills: Sage.

Goffman, E. (2006). Estigma. Buenos Aires: Amorrortu.

Golding, P. \& Elliott, P. (1979). Making the News. Londres: Longman.

González, H. \& Costantini, M. (1992). La realidad satírica: Doce hipótesis sobre Página/12. Buenos Aires: Paradiso Ediciones.

Hughes, E. (2012). Men and their work. California: Forgotten Books.

Lemieux, C. (2010). Introduction. L'autonomie, nécessité de la practique journalistique. En Lemieux, C. (comp.). La subjectivité journalistique (pp. 25-45). París: Éditions de l'École des Hautes Études en Sciences Sociales.

Martini, S. (2004). Periodismo, noticia y noticiabilidad. Buenos Aires: Norma.

McCombs, M. \& Shaw, D. (1972). The Agenda-setting function of the mass media. Public Opinion Quarterly, 36, 176-187.

Park, R. (1950). Race and Culture. Glencoe: Free Press.

Pereyra, S. (2013). Política y transparencia. Buenos Aires: Siglo XXI.

Restrepo, E. (2016).Etnografía: alcances, técnicas y éticas. Bogotá: Pontificia Universidad Javeriana/Envión.

Rodrigo Alsina, M. (1993). La construcción de la noticia. Barcelona: Paidós.

Schlesinger, P. (1987). Putting "reality" together: BBC News. Londres: Methuen.

Sindicato de Prensa de Buenos Aires (2017). 2016: un año de despidos, precarización y ajuste salarial en los medios de comunicación. Obtenido de http://www.sipreba. org/notas/2016-un-ano-de-despidos-precarizacion-y-ajuste-salarial-en-losmedios-de-comunicacion.

Tuchman, G. (1983). La producción de la noticia. Barcelona: Gustavo Gili.

Wolf, M. (1987). La investigación de la comunicación de masas. Barcelona: Paidós. 